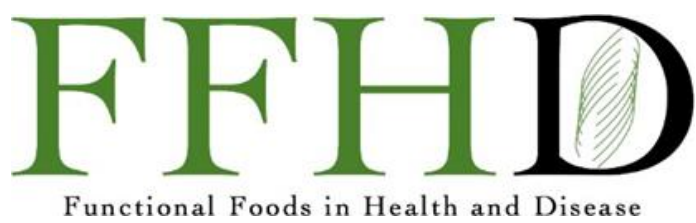

\title{
Eryngium caeruleum essential oil as a promising natural additive: in vitro antioxidant properties and its effect on lipid oxidation of minced rainbow trout meat during storage at refrigeration temperature
}

\author{
Sara Bani Khademi ${ }^{1}$, Majid Aminzare ${ }^{1^{*}}$, Hassan Hassanzadazar ${ }^{1}$, Mohammad Reza Mehrasbi ${ }^{1}$
}

${ }^{1}$ Department of Food Safety and Hygiene, School of Public Health, Zanjan University of Medical Sciences, Zanjan, Iran

*Corresponding Author: Majid Aminzare, Department of Food Safety and Hygiene, School of Public Health, Parvin Etesami Blvd, Ansarieh, Zanjan, Iran.

Submission Date: December 19th 2020 ; Acceptance Date: January 19th , 2021; Publication Date: January 27th, 2021

Please cite this article as: Khademi S.B., Aminzare M., Hassanzadazar H., Mehrasbi M.R. Eryngium caeruleum essential oil as a promising natural additive: in vitro antioxidant properties and its effect on lipid oxidation of minced rainbow trout meat during storage at refrigeration temperature. Functional Foods in Health and Disease 2021. 11(1): 11-23. DOI: https://www.doi.org/10.31989/ffhd.v11i1.766

\begin{abstract}
Background: One of the most common species of oily fish is rainbow trout. Chemical deterioration of oily fish species is principally caused by lipid oxidation. The adverse effects of various chemical preservatives caused consumer's attention to shift to natural alternatives. Eryngium caeruleum is an herbaceous plant that is native to the northern areas of Iran and is used in various local foods. The aim of the present study was to investigate the effects of different concentrations of $E$. caeruleum essential oil (EEO) on the physicochemical and oxidative stability of minced rainbow trout meat for 20 days storage at $4 \pm 1^{\circ} \mathrm{C}$.

Methods: Firstly, the chemical compounds and total phenolic content of EEO were determined by gas chromatography-mass spectrometry and Folin-Ciocalteu reagent, respectively. Then, in vitro antioxidant capacity of EEO was evaluated using 2,2-Diphenyl-1-picrylhydrazyl (DPPH) and 2,2'-azino-bis (3ethylbenzthiazoline-6-sulphonic acid) (ABTS) methods. Finally, the minced rainbow trout meat was mixed with different concentrations of EEO, and physicochemical and oxidative stability of treatments were investigated for 20 days storage at $4 \pm 1^{\circ} \mathrm{C}$.
\end{abstract}


Results: According to the results, $0.4 \%$ EEO significantly improved the chemical stability of minced fish compared to control group at the end of storage period with the following scores $(P<0.05)$ : $\mathrm{pH}$ value (6.3), peroxide value ( $11.88 \mathrm{meq} / \mathrm{kg}$ of lipid) and thiobarbituric acid reactive substance (0.43 mg MDA/kg sample).

Conclusions: In order to increase the chemical quality characteristics of minced fish, new ingredient systems that are associated with natural and organic foods are applied. The results of present study indicate that the use of EEO in the meat industry can develop the novel healthy fish products and improve its chemical stability.

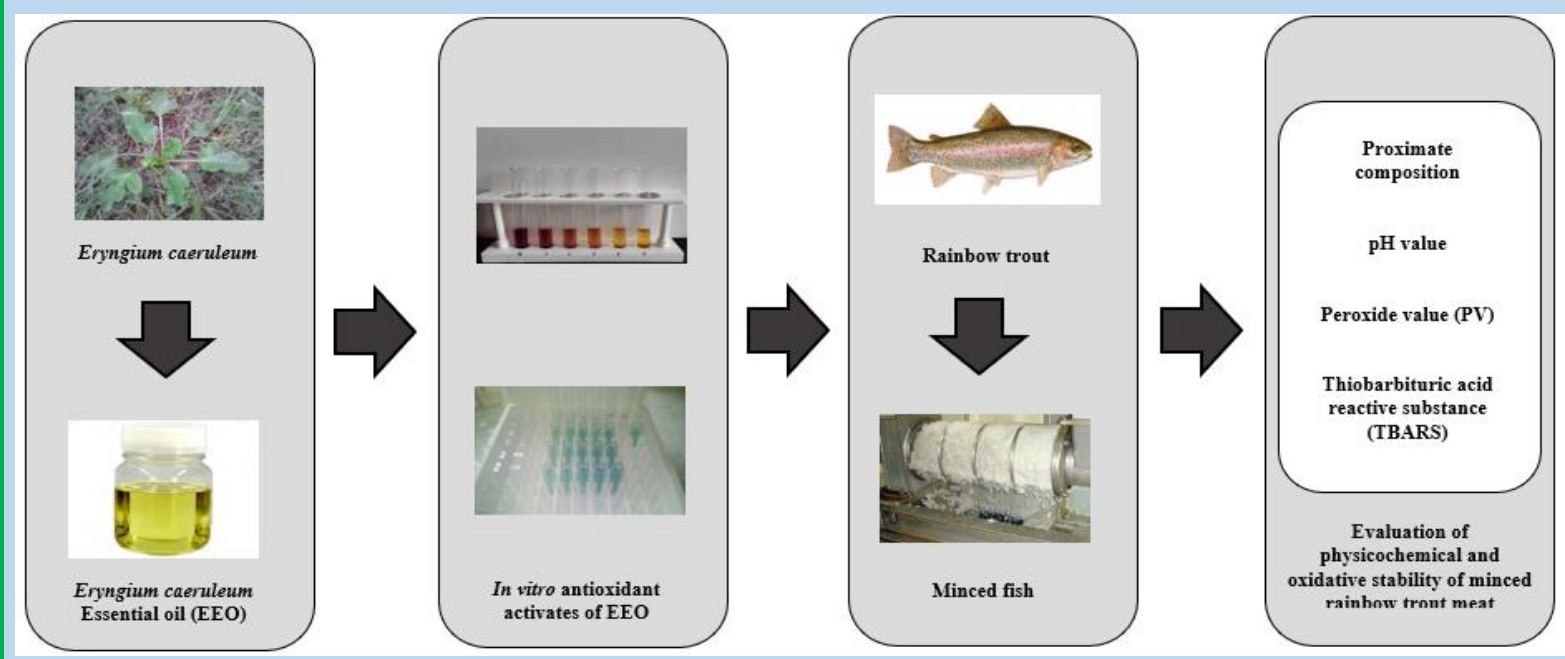

Keywords: Eryngium caeruleum, Oncorhynchus mykiss, Natural antioxidant, Chemical stability, Lipid oxidation.

CFFC 2021. This is an Open Access article distributed under the terms of the Creative Commons Attribution 4.0 License (http://creativecommons.org/licenses/by/4.0)

\section{BACKGROUND}

Oxidation processes that occur in food systems affect several interactions among food ingredients, causing unfavorable products. Food lipids are susceptible to oxidation processes, so lipid oxidation reactions are one of the important sources of deterioration that may happen during processing, manufacturing, storage, distribution, and final preparation of foods [1]. Lipid oxidation is also responsible for the accumulation of disadvantageous compounds, which might be connected with higher occurrence and mortality rates of human diseases including cancer, atherosclerosis, and heart disorders [2].

Fish is considered as one of the healthiest sources of energy for human that contains considerable amounts of vitamins, proteins, major nutrients, and omega-3 polyunsaturated fatty acids (PUFAs) that can diminish the risk of heart diseases. Furthermore, omega-3s contribute to normal neurodevelopment of children. The decrease of total PUFAs in fish meat considerably associates with the rate of lipid oxidation [3-4]. One of the major concerns of consumers and industries is fresh fish quality. The process of lipid oxidation of fish meat initiates instantly after fishing which continues not only with storage but also processing as well. The rate of lipid oxidation in fish meat depends on important factors including grinding or mincing, the composition and quality of raw meat, the use of additives such as antioxidants, and insufficient temperature of cold storage [5]. One of the most common species of oily fish is rainbow trout (Oncorhynchus mykiss) [6]. Lipid oxidation has considerable effect on quality deterioration of oily fish species like rainbow trout [7].

Antioxidants are compounds that can retard or avoid initiating lipid oxidation. Some synthetic antioxidants have been considered to delay the 
lipid oxidation, particularly in food production systems. However, the adverse effects of synthetic antioxidants on human health (such as potential carcinogenic risks) have led to their use being under strict regulation. On the other hand, consumer demand for the replacement of synthetic antioxidants with natural compounds is increasing nowadays. For these reasons, researchers have recently focused on natural alternatives including essential oils (EOs) for use in the food industry [8].

The genus Eryngium includes about 250 different species around the world. It is the largest genus in the family Apiaceae and accounts for approximately three-quarters of the species diversity in the subfamily Saniculoideae [9-10]. Eryngium species, such as the Eryngium campestre, were used as alternative medicine in different countries like Turkey [11]. In China, Eryngium foetidum is used for its anti-inflammatory properties [12]. The species Eryngium caeruleum is a flowering and herbaceous plant that grows in the northern regions of Iran. The essential oil of $E$. caeruleum leaves contains volatile compounds that are responsible for its antimicrobial and flavoring properties [13].

According to our literature review, many studies have been conducted on the antioxidant properties of essential oils of various species of Eryngium plant, including E. pseudothoriifolium, $E$. thorifolium, E. tricuspidatum, E. maritimum, E. foetidum, E. triquetrum [10, 14-17]. However, according to the best of our knowledge, no studies have evaluated the antioxidant properties of $E$. caeruleum essential oil in vitro and in food models.

Therefore, the aim of the present study was to 1) determine the chemical composition and total phenolic content of EEO, 2) evaluate the in vitro antioxidant capacity of EEO, 3) investigate the effects of different concentrations of EEO on physicochemical and oxidative stability of minced rainbow trout meat for 20 days storage at $4 \pm 1^{\circ} \mathrm{C}$.

\section{METHODS}

Chemicals and reagents: Chemicals and reagents were provided from the following companies: methanol, sodium carbonate, potassium persulfate, potassium iodide, Folin-Ciocalteu reagent, butylated hydroxytoluene (BHT), 2,2'Azino-bis (3-ethylbenzothiazoline-6-sulfonic acid) (ABTS) anhydrous sodium sulfate, and diethyl ether were purchased from Merck (Merck KGaA, Darmstadt, Germany), 1 1-diphenyl-2picrylhydrazyl (DPPH), 1,1,3,3tetramethoxypropane (TEP) and gallic acid were supplied from Sigma (Sigma-Aldrich, Steinheim, Germany).

Plant material: Fresh young leaves of $E$. caeruleum plant were collected in pre-flowering period from Astara (a county in Gilan Province) in the North region of Iran. The specie was recognized, and voucher numbers of specimen were deposited at the Institute of Medicinal Plants Herbarium, Karaj, Iran (7035-IMPH). The gathered plants were dried at room temperature of $25^{\circ} \mathrm{C}$ for 5 days. Afterwards, a mixer grinder (Pars Khazar, Tehran, Iran) was used to powder the dried leaves for essential oil extraction [13].

Essential oil extraction: Plant powder of $E$. caeruleum was subjected to hydro-distillation using a Clevenger apparatus device (KOL, behr, Düsseldorf, Germany) for $3 \mathrm{~h}$ with a temperature maintained at $100^{\circ} \mathrm{C}$. This procedure was repeated several times to obtain a sufficient amount of EEO for subsequent experiments. The isolated oil was dehydrated with anhydrous sodium sulfate and stored in colored sealed vial in the dark at $4^{\circ} \mathrm{C}$ prior to testing [13].

Essential oil analysis: Chemical compositions of EEO were analyzed by a gas chromatography-mass spectrometry (GC-MS, Hewlett Packard 5890/5972, Palo Alto, CA, USA) using at 70 eV ionization energy, equipped with a HP-5 capillary column phenyl methyl siloxane $(30 \mathrm{~mm} \times 0.25 \mathrm{~mm}, 0.25 \mu \mathrm{m}$ film 
thickness) with helium and the used split ratio was $1: 20$. Oven temperature was preground at $60^{\circ} \mathrm{C}$ for $3 \mathrm{~min}$ and enhanced to $220^{\circ} \mathrm{C}$ for $7 \mathrm{~min}$. Temperature of injector and detector were $230^{\circ} \mathrm{C}$ and $250^{\circ} \mathrm{C}$, respectively. The retention indices of all the compositions were determined based on the Van Den Dool method 5 using $n$-alkanes as standard. Identification of the spectra was carried out using the Willey-229 mass database, the mass spectrum analysis of ingredients and comparison with standard mass spectra and valid sources such as NIST [18].

Total phenolic content of EEO: Total phenolic compounds of EEO was evaluated by FolinCiocalteu's phenol reagent. $500 \mu \mathrm{L}$ of each concentration of EEO in methanol $(0,0.0625,0.125$, $0.25,0.5$ and $1 \mathrm{mg} / \mathrm{mL}$ ) or gallic acid standard were added to $2.25 \mathrm{~mL}$ of distilled water (D.W). Afterward, $250 \mu \mathrm{L}$ of Folin-Ciocalteu's phenol reagent was added at time zero and mixed. Passing $5 \mathrm{~min}, 2 \mathrm{~mL}$ of $7.5 \%$ sodium carbonate solution $(w / v)$ was added and mixed. After incubation for $120 \mathrm{~min}$ at room temperature, absorbance was measured at $760 \mathrm{~nm}$ by a spectrophotometer (HACH, DR 5000, Düsseldorf, Germany) against a provided blank. The blank consisted of $500 \mu \mathrm{L} 50 \%$ (v/v) methanol instead of sample. Gallic acid solution was used as a standard and a calibration curve was prepared. The content of total phenolics was presented as mg gallic acid equivalent per $g$ of the oil [19].

\section{In vitro antioxidant activity of EEO: 1, 1-Diphenyl-}

2-picryl-hydrazyl radical scavenging activity (DPPH): The radical scavenging effect of essential oil was measured by the method described earlier with some modifications [20]. The amount of $50 \mu \mathrm{L}$ of each concentration of EEO $(0,0.0625,0.125$, $0.25,0.5$ and $1 \mathrm{mg} / \mathrm{mL}$ ) in methanol was added to 2 $\mathrm{mL}$ of DPPH methanolic solution $(24 \mu \mathrm{g} / \mathrm{mL})$. The combination was homogenized with a vortex (Lab Genius, London, UK) and kept at room temperature for 60 minutes. The absorbance of the solution was measured in a spectrophotometer at $517 \mathrm{~nm}$. $1 \mathrm{mg} / \mathrm{mL}$ of BHT was applied as a positive control. The capacity of the essential oil for scavenging DPPH radicals was computed based on the following equation:

\% Scavenging activity $=($ Abs DPPH-Abs sample $) /$ AbS DPPH $\times 100$

Where Abs DPPH is the absorbance of the DPPH methanolic solution and Abs sample is the absorbance of the sample (different concentration of EEO).

\section{2, 2-azino bis (3ethylbenzothiazoline-6-sulphonic} acid) radical scavenging activity (ABTS): The antioxidant effect of different concentrations of EEO was measured using ABTS radical decolorization assay. The $2.6 \mathrm{mM}$ potassium persulfate solution and $7.4 \mathrm{mM}$ ABTS solution in D.W were separately prepared and considered as stock solutions. Then the two mentioned solutions were mixed in equal amounts and the resulting solution (working solution) was kept in the dark at room temperature for $12 \mathrm{~h}$. Then $1 \mathrm{~mL}$ of $A B T S$ solution was mixed with $60 \mathrm{~mL}$ methanol, to get an absorbance of approximately 1.1 at $734 \mathrm{~nm}$ using the spectrophotometer. $150 \mu \mathrm{l}$ of each EEO concentration $(0,0.0625,0.125,0.25,0.5$ and 1 $\mathrm{mg} / \mathrm{mL}$ ) was mixed with $2850 \mu$ of ABTS solution and the mixture was left at room temperature in dark conditions for about $2 \mathrm{~h}$. The absorbance was then determined at $734 \mathrm{~nm}$. The blank was provided in the same manner, but using D.W. instead of the sample. BHT $(1 \mathrm{mg} / \mathrm{mL})$ was used as a positive control [21]. The antioxidant capacity was measured using the following equation:

$\%$ Scavenging activity $=($ AbS ABTS-Abs sample $) / A b S$ ABTS $\times 100$

Where AbSABTS is the absorbance of the ABTS solution and Abssample is the absorbance of the sample (different concentration of EEO).

\section{Preparation of fish samples and storage condition:}

Fresh rainbow trout (Oncorhynchus mykiss) were obtained from a cold- water fish farm in Zanjan 
city, Iran. The samples were transferred to the Food Chemistry Laboratory in polystyrene boxes containing ice bags under hygienic conditions. The fish were washed, eviscerated, headed, skinned.

and spiny bones were removed. Then, $2 \mathrm{~kg}$ fish meat was minced two times using a meat grinder (Pars Khazar, Tehran, Iran) and divided into four equal parts. Different concentrations of EEO $(0,0.1 \%$, $0.2 \%$, and $0.4 \% \mathrm{v} / \mathrm{w}$ ) were added to minced fish and mixed to determine the best antioxidant activity. Finally, four groups of minced fish were packed in polyethylene bags and stored at $4 \pm 1^{\circ} \mathrm{C}$ for further evaluations at days $0,4,8,12,16$ and 20 .

\section{Physicochemical analyses Proximate composition}

analyses: Crude lipid and protein, ash, and moisture of fish meat samples were measured following standard methods [22]. Auto Kjeldahl System was used for crude protein measurement after acid digestion. Crude lipid was measured by the ether-extraction assay using a Soxtec System (Soxtec System HT6, Tecator, höganäs, Sweden). Moisture was determined by oven drying at $105^{\circ} \mathrm{C}$ until a constant weight was achieved. Ash content was determined after placing the samples in a muffle furnace at $550^{\circ} \mathrm{C}$ for $24 \mathrm{~h}$.

pH value: Fish meat specimens (20 g) were homogenized (IKA T10 basic homogenizer, Staufen, Germany) with $100 \mathrm{~mL}$ of D.W. for $30 \mathrm{~s}$ and $\mathrm{pH}$ of homogenates were recorded using a $\mathrm{pH}$ meter $\mathrm{pH}$ Meter E520, Metrohm, Herisau, Switzerland). Before $\mathrm{pH}$ measurement, the device was calibrated using $\mathrm{pH}=7$ and $\mathrm{pH}=4$ buffer (BDH Laboratory Supplies) [23].

Lipid Oxidation Measurement of peroxide value (PV): Each $15 \quad \mathrm{~g}$ sample of minced fish was homogenized with a mixture of $60 \mathrm{ml}$ methanol and $30 \mathrm{ml}$ chloroform in a blender (CB15P model, Waring Commercial, Norwalk, USA) for 5 minutes. Then, $\quad 30 \mathrm{ml}$ more of chloroform was added to the mixture and blended for another $30 \mathrm{~s}$. The mixture was poured into the separating funnel and left for $24 \quad h$ to extract the oil. Then, $36 \mathrm{ml}$ of distilled water was added to separate the different phases. After 2 hours, the lower phase was collected in a volumetric flask and placed in a rotary evaporator (Heidolph Instruments, Hei-VAP Series, Schwabach, Germany) to evaporate the solvent [24]. The yield of oil extraction was $~ 7 \%$.

PV was determined by the following instructions: a portion of extracted oil was blended with $25 \mathrm{~mL}$ solution of acetic acid and chloroform (ratio 3:2, $\mathrm{v} / \mathrm{v})$, and then $1 \mathrm{~mL}$ of saturated potassium iodide was added. The mixture was maintained in a dark place for 10 minutes. Then, $30 \mathrm{~mL}$ of D.W. and 1 $\mathrm{mL}$ of freshly prepared $1 \%$ starch were added to the sample. After shaking, the sample was titrated with $0.01 \mathrm{~N}$ sodium thiosulphate until the blue color vanished. The peroxide values were presented as milliequivalents of peroxide oxygen per $\mathrm{kg}$ of lipid (meq/kg of lipid) [25].

Determination of thiobarbituric acid reactive substance (TBARS): $10 \mathrm{~g}$ minced fish sample was homogenized with $35 \mathrm{~mL}$ of cold extraction solution $\left(4^{\circ} \mathrm{C}\right)$ having $4 \%$ perchloric acid and $0.75 \mathrm{~mL}$ of $\mathrm{BHT}$ $(5 \mathrm{mg} / \mathrm{ml}$ ) at $4000 \mathrm{rpm}$ for $2 \mathrm{~min}$. The mixture was then filtered via Whatman No.1 filter paper (Whatman International Ltd., Maidstone, USA) into a $50 \mathrm{~mL}$ Erlenmeyer flask and washed with $5 \mathrm{~mL}$ of D.W. The filtrate was adjusted to $50 \mathrm{~mL}$ with $4 \%$ perchloric acid, and $5 \mathrm{~mL}$ of the filtrate was added to $5 \mathrm{~mL}$ of $0.02 \mathrm{M}$ thiobarbituric acid (TBA) in D.W. A thermostatically controlled water bath was used to heat test tubes for $60 \mathrm{~min}$ at $100^{\circ} \mathrm{C}$ to develop the malonaldehyde-TBA complex followed by cooling for $10 \mathrm{~min}$ with cold tap water. The absorbance was measured at $532 \mathrm{~nm}$ against a blank containing $5 \mathrm{~mL}$ of D.W and $5 \mathrm{~mL}$ of $0.02 \mathrm{M}$ TBA solution. The standard curve was prepared using TEP solution [26].

Statistical analysis: For performing statistical analysis (One-way ANOVA), SPSS statistical Software Version 18 (SPSS Inc., Chicago, USA) was 

used. All experiments were carried out in triplicate. To discover whether there were significant differences between the factors, Tukey's post hoc test between means were made $(\alpha=0.05)$.

\section{RESULTS}

Identification of EEO components: The chemical composition of EEO was listed in Table 1. According to the GC-MS analysis, 32 different compounds were identified, which made up $99.54 \%$ of the total essential oil. Limonene (26.71\%), cyclobuta[1,2:3,4]dicyclooctene-hexadecahydro (24.19\%) and $\beta$-sesquiphellandrene (15.25\%) were the most representative components of EEO, respectively.

Table 1. Chemical composition of Eryngium caeruleum essential oil

\begin{tabular}{|c|c|c|c|c|}
\hline No. & Compound name & $\mathrm{RT}(\min )^{\mathrm{a}}$ & $K \mathbf{I}^{\mathbf{b}}$ & Percentage \\
\hline 1 & Heptanal & 11.23 & 903 & 0.15 \\
\hline 2 & a-Pinene & 11.47 & 939 & 1.87 \\
\hline 3 & n-Heptanol & 12.31 & 964 & 0.42 \\
\hline 4 & Verbenene & 13.57 & 977 & 0.84 \\
\hline 5 & Myrcene & 14.54 & 990 & 1.95 \\
\hline 6 & n-Octanal & 14.89 & 1003 & 1.53 \\
\hline 7 & 8-3-Carene & 15.56 & 1011 & 6.79 \\
\hline 8 & p-Cymene & 16.55 & 1016 & 0.37 \\
\hline 9 & Limonene & 16.69 & 1031 & 26.71 \\
\hline 10 & Benzene acetaldehyde & 17.15 & 1041 & 0.16 \\
\hline 11 & n-Octanol & 18.47 & 1068 & 0.54 \\
\hline 12 & p-Mentha-2,4(8)-diene & 19.65 & 1090 & 0.27 \\
\hline 13 & Linalool & 20.08 & 1098 & 0.42 \\
\hline 14 & cis-p-Mentha-2,8-dien-1-ol & 21.91 & 1133 & 0.18 \\
\hline 15 & Z-4-Decenal & 24.13 & 1182 & 0.13 \\
\hline 16 & trans-Carveol & 25.92 & 1217 & 0.53 \\
\hline 17 & Citronellol & 27.12 & 1234 & 0.38 \\
\hline 18 & Thymol & 29.97 & 1295 & 0.23 \\
\hline 19 & Carvacrol & 30.36 & 1308 & 0.35 \\
\hline 20 & $\beta$-Elemene & 33.74 & 1391 & 0.21 \\
\hline 21 & $\alpha$-cis-Bergamotene & 35.84 & 1438 & 0.72 \\
\hline 22 & $\alpha$-Acoradiene & 37.17 & 1464 & 0.46 \\
\hline 23 & E- $\beta$-Ionone & 38.02 & 1486 & 1.23 \\
\hline 24 & Z- $\alpha$-Bisabolene & 38.65 & 1504 & 2.57 \\
\hline 25 & $\beta$-Bisabolene & 38.94 & 1511 & 1.84 \\
\hline 26 & Myristicin & 39.45 & 1520 & 0.17 \\
\hline 27 & $\beta$-Sesquiphellandrene & 39.61 & 1524 & 15.25 \\
\hline 28 & Widdrol & 41.13 & 1597 & 0.83 \\
\hline 29 & trans-Longipinocarveol & 45.87 & 1691 & 5.28 \\
\hline 30 & $\begin{array}{c}\text { Cyclobuta[1,2:3,4]dicyclooctene, } \\
\text { hexadecahydro }\end{array}$ & 46.16 & 1698 & 24.19 \\
\hline 31 & n-Octadecane & 50.87 & 1795 & 0.28 \\
\hline 32 & n-Hexadecanoic acid & 59.65 & 1992 & 2.69 \\
\hline \multicolumn{2}{|r|}{ Total Identified } & & & 99.54 \\
\hline
\end{tabular}

${ }^{\mathrm{a}} \mathrm{RT}$ : Retention Time ${ }^{\mathrm{b}} \mathrm{KI}$ : Kovat's Index

Total phenolic content of EEO: The total phenolic content of different EEO concentrations is presented in Table 2. These values were in the range of $1.06-4.07 \mathrm{mg} \mathrm{GAE} / \mathrm{g}$ for different concentrations of EEO. As can be seen, the values have been significantly increased with increasing EEO concentrations $(P<0.05)$. The maximum level of total phenolics was $4.07 \mathrm{mg} \mathrm{GAE} / \mathrm{g}$ for $1 \mathrm{mg} / \mathrm{ml}$ EEO 
Table 2. DPPH and ABTS radical scavenging activities, and total phenolic content of Eryngium caeruleum essential oil (EEO) (Mean \pm SD)

\begin{tabular}{|l|l|l|l|}
\hline Sample (mg/ml) & DPPH (\%) & ABTS (\%) & $\begin{array}{l}\text { Total phenolic content } \\
\text { (mg GAE/g) }\end{array}$ \\
\hline EEO (0.0625) & $66.16 \pm 0.43^{\mathrm{a}}$ & $33.42 \pm 2.85^{\mathrm{a}}$ & $1.06 \pm 0.03^{\mathrm{a}}$ \\
\hline EEO (0.125) & $66.48 \pm 0.58^{\mathrm{ab}}$ & $36.39 \pm 1.71^{\mathrm{a}}$ & $1.16 \pm 0.04^{\mathrm{a}}$ \\
\hline EEO (0.25) & $67.09 \pm 0.78^{\mathrm{ab}}$ & $45.52 \pm 0.67^{\mathrm{b}}$ & $1.55 \pm 0.1^{\mathrm{ab}}$ \\
\hline EEO (0.5) & $67.47 \pm 0.94^{\mathrm{ab}}$ & $58.55 \pm 1.40^{\mathrm{c}}$ & $1.87 \pm 0.27^{\mathrm{b}}$ \\
\hline EEO (1) & $68.21 \pm 0.83^{\mathrm{b}}$ & $70.39 \pm 1.53^{\mathrm{d}}$ & $4.07 \pm 0.39^{\mathrm{c}}$ \\
\hline BHT (1) & $82.73 \pm 0.45^{\mathrm{c}}$ & $99.42 \pm 0.28^{\mathrm{e}}$ & ------------ \\
\hline
\end{tabular}

Values followed by different small letters within the same columns are significantly different according to the Tukey's test $(P<0.05)$.

In vitro antioxidant effects of EEO DPPH free radical scavenging activity: The $\mathrm{DPPH}$ radical scavenging effects for different concentrations of essential oil as well as BHT as a positive control are shown in Table 2. Increasing the concentration of EEO has led to an increase in DPPH radical scavenging effect in the range of $66.16 \%$ to $68.21 \%$. Therefore, the lowest and highest radical scavenging effect of EEO were detected in 0.0625 $\mathrm{mg} / \mathrm{mL}$ and $1 \mathrm{mg} / \mathrm{mL}$ concentrations, respectively, with the significant difference $(P<0.05)$. Also, DPPH radical scavenging effect of EEO was lower than $\mathrm{BHT}(82.73)$ at the same concentration $(P<0.05)$.

ABTS free radical scavenging activity of EEO: Table 2 indicates the antioxidant activity of the essential oil by ABTS assay. A concentrationdependent increasing range of $33.42 \%$ to $70.39 \%$ was observed in the antioxidant capacity of EEO $(P<0.05)$. The highest level of radical scavenging activity belonged to the $1 \mathrm{mg} / \mathrm{ml}$ of EEO, which was significantly lower than the radical scavenging activity of BHT at the same concentration $(P<0.05)$.

Effect of EEO on physicochemical and oxidative stability of minced rainbow trout meat Proximate composition: The findings of proximate compositions of minced fish are displayed in Table 3. The mean contents of moisture, protein, lipid, and ash in the fish samples were $73.71 \%, 17.29 \%$, $6.97 \%$ and $1.02 \%$, respectively.

Table 3. Proximate composition of minced fish (rainbow trout) meat (Mean \pm SD)

\begin{tabular}{|c|c|}
\hline Parameters & Amount (\%) \\
\hline Moisture & $73.71 \pm 0.25$ \\
\hline Protein & $17.29 \pm 0.16$ \\
\hline Lipid & $6.97 \pm 0.14$ \\
\hline Ash & $1.02 \pm 0.02$ \\
\hline
\end{tabular}

pH value: Changes in $\mathrm{pH}$ values of samples during storage time are presented in Figure 1 . At the beginning of the storage period, the $\mathrm{pH}$ values of the samples were in the range of 5.1 to 5.2 without 
significant difference between samples $(P>0.05)$. As can be seen, the $\mathrm{pH}$ values of all samples show fluctuations during the storage period. All samples had an increasing trend in $\mathrm{pH}$ values during storage time, but this increment was observed with less intensity in the samples incorporated with EEO $(P<0.05)$. At the end day of the storage period, the lowest and highest $\mathrm{pH}$ levels with the values of 6.3 and 6.7 belonged to $0.4 \%$ EEO and control samples, respectively $(P<0.05)$.

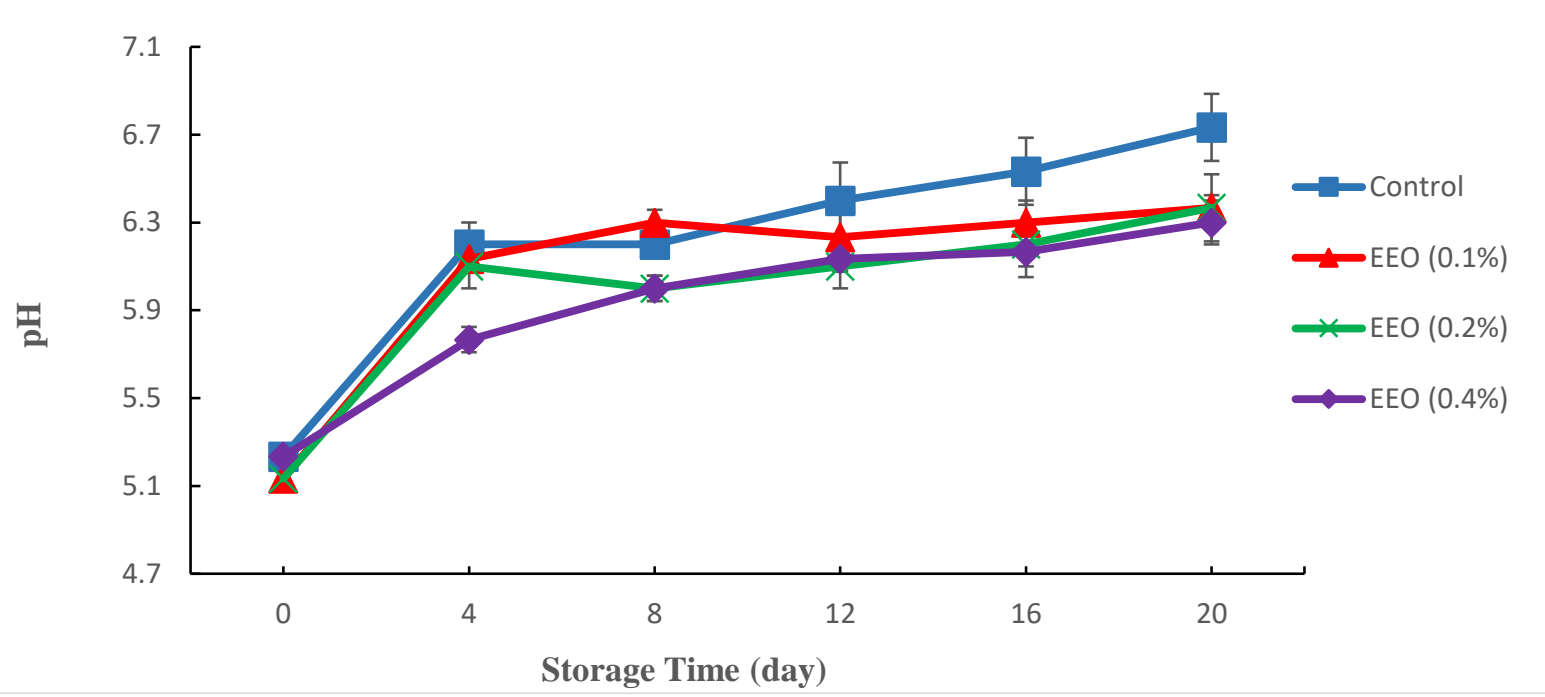

Figure 1. $\mathrm{pH}$ values of minced fish samples containing different concentrations of Eryngium caeruleum essential oil (EEO) for 20 days storage at $4 \pm 1^{\circ} \mathrm{C}$

Changes in peroxide value (PV): Figure 2 shows the changes in PV levels of minced fish samples during 20 days of storage time. The initial PVs of samples were in the range of 7.03 to $7.24 \mathrm{~m} \mathrm{q} / \mathrm{kg}$ of lipid without significant differences between them ( $P>0.05$ ). But on days $4,8,12,16$ and 20, significant differences in PV levels were observed between all groups $(P<0.05)$. The PV levels of control and $0.1 \%$ EEO samples had an increasing trend from 7.24 and $7.15 \mathrm{meq} / \mathrm{kg}$ of lipid to maximum levels of 17.45 and $14.65 \mathrm{meq} / \mathrm{kg}$ of lipid on day 12 and subsequently reduced to the final values of 9.77 and $9.32 \mathrm{meq} / \mathrm{kg}$ of lipid until day 20, respectively $(P<0.05)$. This upward trend in $0.2 \%$ EEO and $0.4 \%$ EEO samples continued until day 16 . In other words, the PV levels of $0.2 \%$ EEO and $0.4 \%$ EEO samples had an increasing trend from 7.19 and $7.03 \mathrm{meq} / \mathrm{kg}$ of lipid to 16.63 and $15.28 \mathrm{meq} / \mathrm{kg}$ of lipid until the 16 th day of storage and then showed a decreasing trend to 12.41 and $11.88 \mathrm{meq} / \mathrm{kg}$ of lipid until day 20 , respectively $(P<0.05)$.

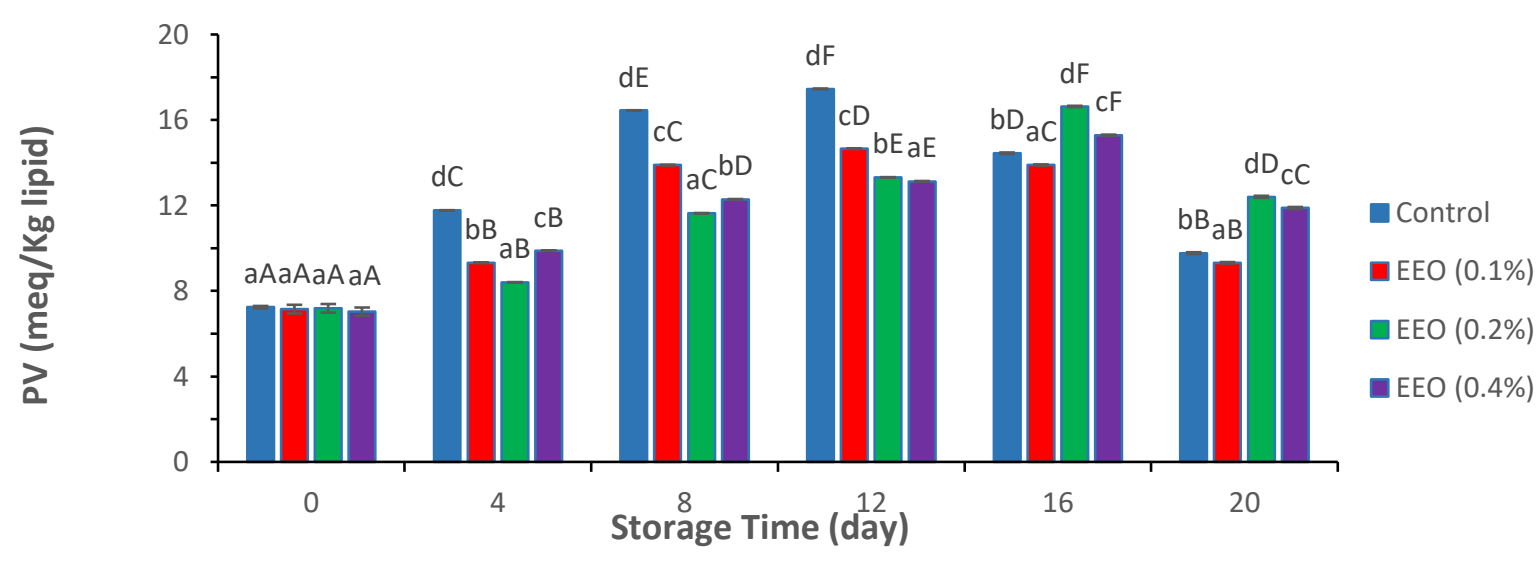

Figure 2. Changes in peroxide values (PV) of minced fish samples containing different concentrations of Eryngium caeruleum essential oil (EEO) for 20 days storage at $4 \pm 1^{\circ} \mathrm{C}$. Values followed by different small letter within the same days and values followed by different capital letter within the same samples are significantly different according to Tukey's Multiple Range Test $(P<0.05)$. 
Changes in thiobarbituric acid reactive substance

(TBARS): The findings of TBARS evaluations of minced fish samples for 20 days storage at refrigeration temperature are shown in Figure 3. The initial TBARS values were in the range of 0.22 to $0.27 \mathrm{mg} \mathrm{MDA} / \mathrm{kg}$ sample without significant difference between them $(P>0.05)$. Ascending trend occurred in treated samples $(0.1 \%, 0.2 \%$ and
$0.4 \%$ EEO) with a lower slope than control group during storage time $(P<0.05)$. TBARS values in all studied groups increased up to day 12 and then decreased until day 20 of storage $(P<0.05)$. The best antioxidant effect belonged to $0.4 \%$ EEO with a TBARS value of $0.43 \mathrm{mg} \mathrm{MDA} / \mathrm{kg}$ sample, which was significantly lower than other groups at the end of the storage period $(P<0.05)$.

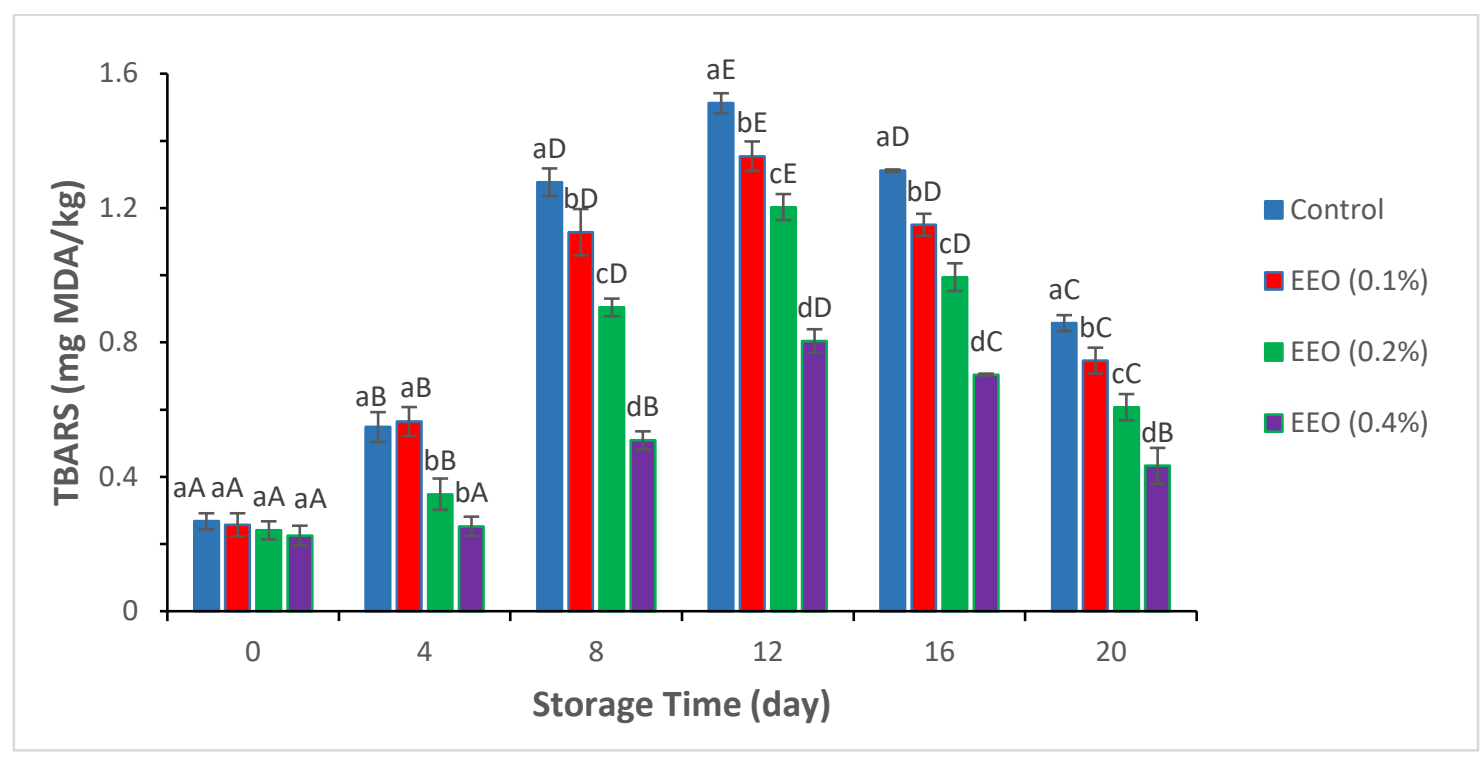

Figure 3. Changes in Thiobarbituric Acid Reactive Substances (TBARS) of minced fish samples containing different concentrations of Eryngium caeruleum essential oil (EEO) for 20 days storage at $4 \pm 1^{\circ} \mathrm{C}$

Values followed by different small letter within the same days and values followed by different capital letter within the same samples are significantly different according to Tukey's Multiple Range Test $(P<0.05)$.

\section{DISCUSSION}

The chemical composition of EEO was listed in Table

1. The findings of GC-MS analysis of EEO were consistent with the results of a study by Mirahmadi et al. (2020), who reported that limonene (25.42\%) andcyclobuta[1,2:3,4]dicyclooctenehexadecahydro (22.24\%) were the main components of EEO, respectively [27]. Assadian et al. (2005) and Semnani et al. (2003) also identified limonene with values of $(60.50 \%)$ and $(52.1 \%)$ as the main component of EEO, respectively [28-29]. However, Dehghanzadeh et al. (2014) indicated that cyclobuta[1,2:3,4]dicyclooctenehexadecahydro (47.03\%) was the major component of $E$. caeruleum essential oil. Differences in the components of EEOs could be attributed to the genetic background such as maturity and cultivar of the plants, harvest season, cultivation conditions, soil and climate changes, differences in the geographical area, the part of the plant used, extraction method, and the solvent used for extraction $[10,30]$.

The total phenolic content of different EEO concentrations is presented in Table 2. The total phenolic content of essential oils is one of the most important indicators of their antioxidant capacity because plant phenols act as chain-breaking peroxyl-radical scavengers. Phenols with two adjacent hydroxyl groups can bind metal ions. They also directly scavenge reactive oxygen [31]. According to our literature review, no studies have been performed to evaluate the total phenolic content of Eryngium spp. essential oils. However, there are few studies on the total phenolic content 
of aqueous and/or alcoholic extracts of different species of Eryngium genus. In the study by Nouri (2020), the total phenolic content of the aqueous extract of $E$. caeruleum was $26.84 \mathrm{mg} \mathrm{GAE} / \mathrm{g}$ [32]. In another study, the total phenol content of hydroalcoholic extract of $E$. maritimum at concentration of $10 \mathrm{mg} / \mathrm{ml}$ was reported $16.44 \mathrm{mg}$ $\mathrm{GAE} / \mathrm{g}$ [33]. According to another research, the total phenolic content of methanolic extract of $E$. caucasicum leaves was $62.3 \mathrm{mg} \mathrm{GAE} / \mathrm{g}$ [34]. Several environmental factors such as climate conditions, geographic location, processing conditions, season of growth, soil type, and storage can affect the rate of phenolic contents of plant essential oils and extracts [35].

The DPPH radical scavenging effects for different concentrations of essential oil as well as BHT as a positive control are shown in Table 2 . Previous studies have reported varying degrees of DPPH scavenging effects by the different Eryngium spp. essential oils and extracts. According to the results by Sadiq et al. (2020) study, crude methanolic extract of $E$. caeruleum in the concentration range of 0.125 to $1 \mathrm{mg} / \mathrm{ml}$ displayed a range of $44.50 \%$ to $73.33 \% \mathrm{DPPH}$ radical scavenging activities [36]. In the study by Merghache et al. (2014), E. tricuspidatum essential oil at concentration of $1,000 \mathrm{mg} / \mathrm{mL}$ exhibited $60.35 \%$ DPPH radical scavenging activity which is weaker than the effects of $E$. caeruleum essential oil in the present study [10]. In another study, the DPPH radical scavenging activity of $E$. foetidum stem, root and leaf oils at a concentration of 100 $\mu \mathrm{g} / \mathrm{ml}$ were $78.08 \%, 67.53 \%$ and $56.76 \%$, respectively, which were stronger than the results of the present study [16]. The antioxidant activity of plant essential oils and extracts is mainly attributed to their compounds. The differences between the results of various studies may be due to the different amounts of the main phenolic compounds in Eryngium species [10]. According to Table 1,
Limonene, cyclobuta[1,2:3,4]dicyclooctenehexadecahydro and $\beta$-sesquiphellandrene were the highest components of EEO, respectively, and probably the most important phenolic compounds responsible for antioxidant capacity of EEO. In addition, the presence of other compounds in small amounts or synergistic effects between them can also affect the results [10].

Table 2 indicated the antioxidant activity of the essential oil by ABTS assay. In the study by Sadiq et al. (2020), the ABTS scavenging effects of 1 $\mathrm{mg} / \mathrm{ml}$ E. caeruleum methanolic extract was $72.30 \%$ which was in agreement with present results about E. caeruleum essential oil in the same concentration [37]. In another study, the ABTS radical scavenging activities of $E$. pseudothoriifolium and E. thorifolium essential oils at a concentration of $0.2 \mathrm{mg} / \mathrm{ml}$ were 63.46 and 49.72 , respectively [14]. The difference in results is due to the presence of various compounds in the essential oils and extracts of different Eryngium species. In this regard, different factors such as the used part of the plant, extraction method and the solvent used for extraction are effective $[10,30]$.

The findings of proximate compositions of minced fish are displayed in Table 3. These values have close similarity to those for rainbow trout, descried by Ozdan et al., (2005) as 18.5 \%, 76.2 $\%, 1.47 \%$ and $3.7 \%$, for protein, moisture, ash, and lipid, respectively [36]. Celik et al, (2008) confirmed the values of protein, moisture, ash, and lipid contents of the rainbow trout meat averaged $19.6 \%, 71.6 \%, 1.3 \%$ and 4.43, respectively [38]. Although current values are favorably comparable with other studies, some differences in the chemical compositions of fish are strongly correlated to some factors including nutrition, fishing season (spawning cycles), sexual differences, fish size, living region, etc. [39].

Changes in $\mathrm{pH}$ values of samples during storage time are presented in Figure 1. The $\mathrm{pH}$ 
increment in samples may be due to the effect of endogenous or microbial enzymes like lipase and protease which increase volatile bases (e.g., trimethylamine and ammonia) during long-term storage [40]. The slow trend of increasing $\mathrm{pH}$ for treated samples can be associated to inhibitory effects of EEO on bacterial growth and subsequently disintegration of amino compounds during storage period [25]. In agreement with the present results, Ehsani et al. (2014) reported a slower increase in the $\mathrm{pH}$ trend of rainbow trout burger containing Zataria multiflora essential oil than control group during 21 days of storage at $4 \pm 1$ ${ }^{\circ} \mathrm{C}[25]$.

Figure 2 shows the changes in PV levels of minced fish samples during 20 days of storage time. Numerous factors affect lipid oxidation including storage temperature, species, and lipid combination [41]. Lipid oxidation is considered as a complicated procedure of free radical-mediated chain of reactions including launch, propagation, and termination phases. The first products are peroxides that are converted to secondary oxidation products including aldehydes, polymers, epoxides, ketones, hydroxy compounds, and oligomers under long-term oxidation conditions [2]. The increasing trend to the maximum level of PVs maybe due to the higher rate of peroxide formation compared to the decomposition of peroxides into secondary oxidation products [42]. The findings of the present study revealed an increasing trend followed by a decreasing trend in PV levels of all experimental groups during the storage period,

which could be due to the degradation of hydroperoxides into smaller molecules [25]. Also, the increasing trend in samples containing higher essential oil (0.2\% EEO and 0.4\% EEO) had a slower slope than the control and $0.1 \%$ EEO samples due to the delay in lipid oxidation and hydroperoxides production. In agreement with the present results, Ehsani et al. (2014) found that Z. multiflora Boiss essential oil could slow down the increasing trend of PV levels in fish burger samples compared to the control group [25].

The findings of TBARS evaluations of minced fish samples for 20 days storage at refrigeration temperature are shown in Figure 3. The decrease in TBARS values from day 12 to the end of the storage period may be due to the breakdown of MDA into tertiary metabolites, which may result from several interactions between MDA and proteins, amino acids, glucose, and other fish compounds [25]. Our findings are consistent with the results of other studies that have reported that the use of essential oils could slow down the increasing trend of TBARS values in rainbow trout meat samples compared to the control group $[25,39,43]$.

\section{CONCLUSION}

The results of present study showed that the essential oil of E. caeruleum is capable of retarding the chemical deterioration and subsequently improving the chemical quality of minced rainbow trout meat. This essential oil at a concentration of $0.4 \%$ showed the best effect in inhibiting lipid oxidation of minced fish. Therefore, the authors suggest considering E. caeruleum essential oil as a natural antioxidant additive in fish meat due to its antioxidant properties. However, the impact of this essential oil on other types of meat products using different packaging techniques for long-term storage must be assessed.

Competing Interests: Authors declare that they have no conflict of interest.

Author's Contribution: Sara Bani Khademi carried out the experiment. Majid Aminzare wrote the manuscript. Majid Aminzare and Hassan Hassanzadazar supervised the project. Mohammad 
Reza Mehrasbi conceived the original idea. All

authors read and approved the final manuscript.

Acknowledgements and Funding: This work was

financially supported by the School of Public Health,

Zanjan University of Medical Science, Zanjan, Iran

(project code: A-12-964-3).

List of Abbreviations: EEO: E. caeruleum essential oil, DPPH: 2,2-Diphenyl-1-picrylhydrazyl, ABTS: 2,2'-

\section{REFERENCES}

1. Shahidi F, Zhong Y: Novel antioxidants in food quality preservation and health promotion. Eur. J. Lipid. Sci. Technol. 2010,112(9), 930-940.

2. Tan Z, Shahidi F: Antioxidant activity of phytosteryl phenolates in different model systems. Food chem. 2013, 138(2-3), 1220-1224.

3. Mozaffarian D, Wu JH: Omega-3 fatty acids and cardiovascular disease: effects on risk factors, molecular pathways, and clinical events. JACC CardioOncol. 2011, 58(20), 2047-2067.

4. Swanson D, Block R, Mousa SA: Omega-3 fatty acids EPA and DHA: health benefits throughout life. Adv. Nutr. 2012, 3(1), 1-7.

5. Mariutti LR, Bragagnolo $\mathrm{N}$ : Influence of salt on lipid oxidation in meat and seafood products: A review. Food Res, Int. 2017, 94, 90-100.

6. Hodge L, Salome CM, Peat JK, Haby MM, Xuan W, Woolcock AJ: Consumption of oily fish and childhood asthma risk. Med. J. Australia. 1996, 164(3), 137-140.

7. Rezaei M, Hosseini S: Quality assessment of farmed rainbow trout (Oncorhynchus mykiss) during chilled storage. J. Food Sci. 2008, 73(6).

8. Aminzare $\mathrm{M}$, Hashemi $\mathrm{M}$, Ansarian E, Bimkar M, Azar H, Mehrasbi MR, et al: Using natural antioxidants in meat and meat products as preservatives: A review. Adv. Anim. Vet. Sci. 2019, 7(5), 417-426

9. Calvino $\mathrm{Cl}$, Martínez SG, Downie SR: The evolutionary history of Eryngium (Apiaceae, Saniculoideae): Rapid radiations, long distance dispersals, and hybridizations. Mol. Phylogenet. Evol. 2008, 46(3), 1129-1150.

10. Merghache D, Boucherit-Otmani Z, Merghache S, Chikhi I, Selles C, Boucherit K: Chemical composition, antibacterial, antifungal and antioxidant activities of Algerian Eryngium tricuspidatum L. essential oil. Nat. Prod. Res. 2014, 28(11), 795-807.

11. Küpeli E, Kartal M, Aslan S, Yesilada E: Comparative evaluation of the anti-inflammatory and antinociceptive activity of Turkish Eryngium species. J. Ethnopharmacol. 2006, 107(1), 32-37.

12. Wang P, Su Z, Yuan W, Deng G, Li S: Phytochemical constituents and pharmacological activities of Eryngium L.(Apiaceae). Pharm. Crop. 2012, 3, 99-120.

13. Dehghanzadeh N, Ketabchi S, Alizadeh A: Essential oil composition and antibacterial activity of Eryngium caeruleum grown wild in Iran. Journal of Essential Oil Bearing Plants. 2014, 17(3), 486-492.

14. Tel-Çayan G, Duru ME: Chemical characterization and antioxidant activity of Eryngium pseudothoriifolium and azino-bis (3-ethylbenzthiazoline-6-sulphonic acid), PUFAs: polyunsaturated fatty acids, EOs: essential oils, BHT: butylated hydroxytoluene, TEP: tetramethoxypropane, D.W: distilled water, NIST: National Institute of Standards and Technology, PV: peroxide value, TBARS: thiobarbituric acid reactive substance, TBA: thiobarbituric acid.

E. thorifolium essential oils. Marmara Pharm. J. 2019, 23(6).

15. Darriet F, Andreani S, De Cian MC, Costa J, Muselli A: Chemical variability and antioxidant activity of Eryngium maritimum L. essential oils from Corsica and Sardinia. Flavour Fragr. J. 2014, 29(1), 3-13.

16. Thomas PS, Essien EE, Ntuk SJ, Choudhary MI: Eryngium foetidum L. essential oils: chemical composition and antioxidant capacity. Medicines. 2017, 4(2), 24.

17. Medbouhi A, Merad N, Khadir A, Bendahou M, Djabou $\mathrm{N}$, Costa J, et al: Chemical composition and biological investigations of Eryngium triquetrum essential oil from Algeria. Chem. biodiversity. 2018, 15(1), e1700343.

18. Moradi M, Hassani A, Ehsani A, Hashemi M, Raeisi M, Naghibi S: Phytochemical and antibacterial properties of Origanum vulgare ssp. gracile growing wild in Kurdistan province of Iran. J. Food Qual. Hazards Control. 2014, 1(4), 120-124.

19. Singleton VL, Rossi JA: Colorimetry of total phenolics with phosphomolybdic-phosphotungstic acid reagents. Am. J. Enol. Vitic. 1965, 16(3), 144-58.

20. Blois MS: Antioxidant determinations by the use of a stable free radical. Nature. 1958, 181(4617), 1199-1200.

21. Thaipong K, Boonprakob U, Crosby K, Cisneros-Zevallos $\mathrm{L}$, Byrne DH: Comparison of ABTS, DPPH, FRAP, and ORAC assays for estimating antioxidant activity from guava fruit extracts. J. Food Compost. Anal. 2006, 19(67), 669-675.

22. AOAC: Official Methods of Analysis of the Association of Official Analytical Chemistry. 16th ed. Washington, USA. AOAC International. 1995, 1141.

23. Ehsani A, Hashemi M, Raeisi M, Naghibi SS, Afshari A: Rainbow trout fillet biopreservation by edible chitosanbased coating containing egg yolk antibody (IgY) and lycopene. J. Food Sci. Technol. 2020, 57(1), 282-292.

24. Mohammad ZB, Rezaei M: Effective of green tea extract on lipid quality of rainbow trout (Oncorhynchus Mykiss) during in ice storage. J. Fish. 2011, 64(1), 85-93 (In Persian)

25. Ehsani A, Jasour MS, Hashemi M, Mehryar L, Khodayari M: Zataria multiflora Boiss essential oil and sodium acetate: how they affect shelf life of vacuum-packaged trout burgers. Int. J. Food Sci. Technol. 2014, 49(4), 1055-1062.

26. Pikul J, Leszczynski DE, Kummerow FA: Evaluation of three modified TBA methods for measuring lipid oxidation in chicken meat. J. Agric. Food Chem. 1989, 37(5), 1309-1313. 
27. Mirahmadi SS, Aminzare M, Azar HH, Kamali K: Effect of Eryngium caeruleum essential oil on microbial and sensory quality of minced fish and fate of Listeria monocytogenes during the storage at $4^{\circ} \mathrm{C}$. J. Food. Saf. 2020, 40(2), e12745.

28. Assadian F, Masoudi S, Nematollahi F, Rustaiyan A, Larijani K, Mazloomifar $\mathrm{H}$ : Volatile constituents of Xanthogalum purpurascens Ave-Lall., Eryngium caeruleum $\mathrm{MB}$ and Pimpinella aurea DC. Three Umbelliferae herbs growing in Iran. J. Essential Oil Res. 2005, 17(3), 243-245.

29. Semnani K, Azadbakht M, Houshmand A: Composition of the essential oils of aerial parts of Eryngium bungei Boiss. and Eryngium caeruleum MB. Pharm. Sci. 2003, 1, 43-48 (In Persian).

30. Mahmoudvand $H$, Mirbadie SR, Sadooghian S, Harandi MF, Jahanbakhsh S, Saedi Dezaki E: Chemical composition and scolicidal activity of Zataria multiflora Boiss essential oil. J. Essential Oil Res. 2017, 29(1), 4247.

31. Miguel MG: Antioxidant activity of medicinal and aromatic plants. A review. Flavour Fragr. J. 2010, 25(5), 291-312.

32. Nouri M: Preparation of nanoliposomes containing Hyssopus officinalis L. and Eryngium caeruleum M. Bieb extracts and investigate their antimicrobial and antimicrobial effects. J. Med. Plants. 2020, 19(75), 118131 (In Persian).

33. Meot-Duros L, Le Floch G, Magné C: Radical scavenging, antioxidant and antimicrobial activities of halophytic species. J. Ethnopharmacol. 2008, 116(2), 258-262.

34. Nabavi S, Ebrahimzadeh $M$, Nabavi $S$, Jafari $M$ : Free radical scavenging activity and antioxidant capacity of Eryngium caucasicum Trautv and Froripia subpinnata. Pharmacologyonline. 2008, 3, 19-25.

35. Aliakbarlu J, Sadaghiani SK, Mohammadi S: Comparative evaluation of antioxidant and anti food-borne bacterial activities of essential oils from some spices commonly consumed in Iran. Food Sci. Biotechnol. 2013, 22(6), 1487-1493.

36. Sadiq A, Rashid U, Ahmad S, Zahoor M, AlAjmi MF, Ullah $\mathrm{R}$, et al: Treating Hyperglycemia From Eryngium caeruleum M. Bieb: In-vitro $\alpha$-Glucosidase, Antioxidant, in-vivo Antidiabetic and Molecular Docking-Based Approaches. Front. Chem. 2020, 8, 1064.

37. Özden Ö: Changes in amino acid and fatty acid composition during shelf-life of marinated fish. J. Sci. Food Agric. 2005, 85(12), 2015-2020.

38. Celik M, Goekce MA, Başusta N, Kuecuekguelmez A, Taşbozan O, Tabakoğlu şs: Nutritional quality of rainbow trout (Oncorhynchus mykiss) caught from the Atatürk Dam Lake in Turkey. Journal of Muscle Foods. 2008, 19(1), 50-61.

39. Ojagh SM, Rezaei M, Razavi SH, Hosseini SMH: Effect of chitosan coatings enriched with cinnamon oil on the quality of refrigerated rainbow trout. Food chem. 2010, 120(1), 193-198.

40. Chaijan M, Benjakul S, Visessanguan W, Faustman C: Changes of pigments and color in sardine (Sardinella gibbosa) and mackerel (Rastrelliger kanagurta) muscle during iced storage. Food chem. 2005, 93(4), 607-617.

41. Jasour MS, Rahimabadi EZ, Ehsani A, Rahnama M, Arshadi A: Effects of refrigerated storage on fillet lipid quality of rainbow trout (Oncorhynchus mykiss) supplemented by $\alpha$-tocopheryl acetate through diet and direct addition after slaughtering. J Food Process Technol. 2011, 2(124), 2.
42. Bazargani-Gilani B, Aliakbarlu J, Tajik H: Effect of pomegranate juice dipping and chitosan coating enriched with Zataria multiflora Boiss essential oil on the shelf-life of chicken meat during refrigerated storage. Innov. Food Sci. Emerg. Technol. 2015, 29, 280287.

43. Alparslan $\mathrm{Y}$, Baygar $\mathrm{T}$, Baygar $\mathrm{T}$, Hasanhocaoglu $\mathrm{H}$, Metin C. Effects of gelatin-based edible films enriched with laurel essential oil on the quality of rainbow trout (Oncorhynchus mykiss) fillets during refrigerated storage. Food Technol. Biotechnol. 2014, 52(3), 325333. 